\title{
Synthesis of six-membered silacycles by borane-catalyzed double sila-Friedel-Crafts reaction
}

\author{
Yafang Dong $^{1}$, Masahiko Sakai ${ }^{1}$, Kazuto Fuji ${ }^{1}$, Kohei Sekine ${ }^{1,2}$ and Yoichiro Kuninobu ${ }^{*} 1,2$
}

\section{Letter}

\section{Address:}

${ }^{1}$ Interdisciplinary Graduate School of Engineering Sciences, Kyushu University, 6-1 Kasugakoen, Kasuga-shi, Fukuoka 816-8580, Japan and ${ }^{2}$ Institute for Materials Chemistry and Engineering, Kyushu University, 6-1 Kasugakoen, Kasuga-shi, Fukuoka 816-8580, Japan

Email:

Yoichiro Kuninobu* - kuninobu@cm.kyushu-u.ac.jp

* Corresponding author

Keywords:

borane; cyclic compound; organosilane; sila-Friedel-Crafts; silylation
Beilstein J. Org. Chem. 2020, 16, 409-414. doi:10.3762/bjoc. 16.39

Received: 01 February 2020

Accepted: 11 March 2020

Published: 17 March 2020

This article is part of the thematic issue "C-H functionalization for materials science".

Guest Editor: K. Itami

(C) 2020 Dong et al.; licensee Beilstein-Institut.

License and terms: see end of document.

\section{Abstract}

We have developed a catalytic synthetic method to prepare phenoxasilins. A borane-catalyzed double sila-Friedel-Crafts reaction between amino group-containing diaryl ethers and dihydrosilanes can be used to prepare a variety of phenoxasilin derivatives in good to excellent yields. The optimized reaction conditions were also applicable for diaryl thioethers to afford their corresponding six-membered silacyclic products. The gram-scale synthesis of a representative bis(dimethylamino)phenoxasilin and the transformation of its amino groups have also been demonstrated.

\section{Introduction}

Six-membered silacyclic compounds, such as phenoxasilin and phenothiasilin derivatives, are attractive compounds for applications as organic electronic materials [1-4], ligands [5-10], and reagents [11-14]. Therefore, the development of new methods to construct silacyclic skeletons is highly desirable. These compounds are commonly synthesized upon the reaction of heteroatom-bridged dilithiated diaryl compounds, such as dilithiated diaryl ethers and dilithiated diaryl thioethers with a range of dichlorosilane derivatives (Scheme 1a) [15-24]. An intramolecular silylation via $\mathrm{Si}-\mathrm{C}$ bond cleavage can also be used to prepare a variety of six-membered silacyclic derivatives (Scheme 1b) [25]. However, some problems still remain in terms of the functional group tolerance and versatility of these previously reported synthetic methods due to the use of a stoichiometric amount of the organolithium reagents. In addition, despite these contributions, catalytic reaction systems have not been developed as much [26,27].

The sila-Friedel-Crafts reaction is emerging as a powerful tool for C-H silylation [28,29]. In addition, intra- and intermolecular sila-Friedel-Crafts reactions have been recently developed [30-39], which have great potential as efficient synthetic strategies to construct silacycles. For example, the intramolecular $\mathrm{C}-\mathrm{H}$ silylation of biphenylhydrosilanes can be used to prepare various silafluorene derivatives [30-34] and the ruthenium-catalyzed intermolecular Friedel-Crafts-type reaction of 
a)

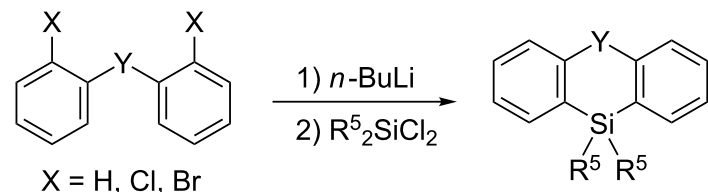

$\mathrm{Y}=\mathrm{O}, \mathrm{S}, \mathrm{NR}^{1}, \mathrm{PR}^{2}, \mathrm{CR}^{3}{ }_{2}, \mathrm{SiR}^{4}{ }_{2}$

b)

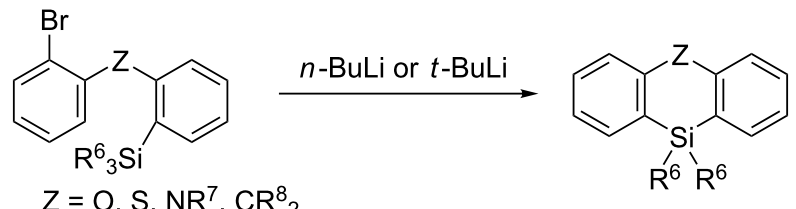

c) this work<smiles>[R10]Nc1cccc(Cc2cccc([N+](=O)[O-])c2)c1</smiles>

$\mathrm{H}_{2} \mathrm{SiR}^{11} \mathrm{R}^{12}$

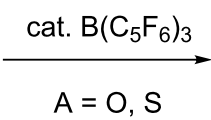

$A=0, S$<smiles>[R10]Nc1ccc2c(c1)Cc1cc([N+]([R16])=O)ccc1[Si]2([R17])[R17]</smiles>

Scheme 1: Synthetic methods of six-membered silacyclic compounds.

2-phenylindole with a variety of dihydrosilanes affords indolefused benzosiloles [39]. We have also contributed to the synthesis of silafluorenes from biphenyls and dihydrosilanes using a borane-catalyzed double sila-Friedel-Crafts reaction [40,41] Subsequently, we envisaged that the catalytic reaction between diaryl ethers and dihydrosilanes may be a useful protocol to prepare phenoxasilin derivatives (Scheme 1c). Herein, we report a borane-catalyzed double sila-Friedel-Crafts reaction used for the synthesis of six-membered silacyclic compounds, such as phenoxasilin and phenothiasilin derivatives.

\section{Results and Discussion}

A double sila-Friedel-Crafts reaction was initially investigated using diaryl ether 1a and dihydrodiphenylsilane (2a) as model substrates (Table 1). Under the optimized reaction conditions used for the synthesis of silafluorenes in our previous report [40] $\left(\mathrm{B}\left(\mathrm{C}_{6} \mathrm{~F}_{5}\right)_{3}(5.0 \mathrm{~mol} \%)\right.$ and 2,6-lutidine $(7.5 \mathrm{~mol} \%)$ in chlorobenzene at $100{ }^{\circ} \mathrm{C}$ ), the desired reaction between $1 \mathrm{a}$ with 2a proceeded to give phenoxasilin 3a in $60 \%$ yield (Table 1, entry 1). The structure of phenoxasilin 3a was confirmed using single-crystal X-ray crystallography (see Supporting Information File 1 for details) [42]. Upon increasing the reaction temperature to $140{ }^{\circ} \mathrm{C}$, the yield of $\mathbf{3 a}$ was improved to $88 \%$ (Table 1, entry 2). Although the reaction in the presence of $3.0 \mathrm{~mol} \%$ of the catalyst also proceeded efficiently (Table 1 , entry 3 , conditions A), the yield of $\mathbf{3 a}$ decreased when compared to that obtained using $1.5 \mathrm{~mol} \%$ of the catalyst (Table 1 , entry 4). The best result was obtained in the absence of 2,6-luti-

Table 1: Optimization of the reaction conditions for the synthesis of phenoxalin $\mathbf{3 a}$.<smiles>CN(C)c1cccc(Oc2cccc(N(C)C)c2)c1</smiles>

2a

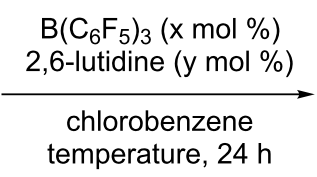

chlorobenzene
temperature, $24 \mathrm{~h}$<smiles>CN(C)c1ccc2c(c1)Oc1cc(N(C)C)ccc1[Si]2(c1ccccc1)c1ccccc1</smiles>

$3 a$

\begin{tabular}{lllll}
\hline entry & x (mol\%) & y (mol \%) & temp $\left({ }^{\circ} \mathrm{C}\right)$ & 60 \\
\hline 1 & 5.0 & 7.5 & 100 & 88 \\
2 & 5.0 & 7.5 & 140 & 97 \\
3 & 3.0 & 7.5 & 140 & 87 \\
5 & 1.5 & 7.5 & 140 & 99 \\
\hline
\end{tabular}

a 1a $(0.250 \mathrm{mmol}), 2 \mathrm{a}(0.750 \mathrm{mmol})$, chlorobenzene $(0.4 \mathrm{~mL})$. 
dine by which phenoxasilin 3a formed in 99\% yield (Table 1, entry 5 , conditions B).

Next, the scope of the dihydrosilane starting materials used in the reaction was investigated (Scheme 2). The reactions of phenylmethylsilane (2b) and diethyldihydrosilane (2c) afforded their corresponding phenoxasilin derivatives $\mathbf{3 b}$ and $\mathbf{3 c}$ in 66 and $74 \%$ yield, respectively. The yields of $\mathbf{3 b}$ and $\mathbf{3 c}$ were improved to 83 and $91 \%$ in the presence of a catalytic amount of 2,6-lutidine, probably due to the acceleration of the deprotonation step by 2,6-lutidine [33]. In the case of phenylsilane (2d), the phenoxasilin product $\mathbf{3 d}$ was formed in 59\% yield using conditions B and in 63\% yield under conditions A. Di(4-bromophenyl)dihydrosilane (2e) was transformed successfully into phenoxasilin $3 \mathbf{e}$ in $83 \%$ yield without loss of the bromine substituent. The reaction system was also applicable for 9,9dihydro-5-silafluorene (2f), which gave the spiro-type phenoxasilin $\mathbf{3 f}$ in $96 \%$ yield.

We then investigated the scope of the starting biaryl ethers used in the reaction as well as related derivatives thereof using dihydrodiphenylsilane (2a, Scheme 3). Pyrrolidine-substituted diaryl ether $\mathbf{1 b}$ was transformed into phenoxasilin $\mathbf{3 g}$ in $80 \%$ yield.
Also, the chloro-substituted diaryl ether gave its corresponding phenoxasilin $\mathbf{3 h}$ in $94 \%$ yield without affecting the chlorine substituent. The methyl-substituted phenoxasilin derivatives $\mathbf{3 i}$ and $\mathbf{3} \mathbf{j}$ were formed in good yield despite of the steric hindrance of the methyl group in $\mathbf{3 j}$. When one of the $\mathrm{NMe}_{2}$ groups was replaced with a SMe group, a mixture of the corresponding phenoxasilin product (3k) and the hydrosilane compound (3k') was obtained via a single sila-Friedel-Crafts reaction in $35 \%$ yield in the presence of 2,6-lutidine $\left(3 \mathbf{k}: 3 \mathbf{k}^{\prime}=63: 37\right)$. This result was probably due to the weaker electron-donating ability of the SMe group compared to that of $\mathrm{NMe}_{2}$. The double $\mathrm{C}-\mathrm{H}$ silylation reaction proceeds efficiently upon increasing the temperature to $180{ }^{\circ} \mathrm{C}$ that afforded the mixture $\left(\mathbf{3 k}: \mathbf{3} \mathbf{k}^{\prime}=92: 8\right)$ in $68 \%$ yield. The reaction system can also be applied to the synthesis of phenothiasilin 31 that was obtained in $93 \%$ yield starting from diaryl thioether 1g. $N$-(Benzyl)methylaminesubstituted diaryl thioether $\mathbf{1 h}$ was also transformed into phenothiasilin $\mathbf{3 m}$ in 58\% yield. The corresponding six-membered silacycles were not formed using $N$-aryl-bridged biaryls as substrates.

To test the applicability of the method, a gram-scale synthesis of phenoxasilin 3a was carried out (Scheme 4). The reaction of
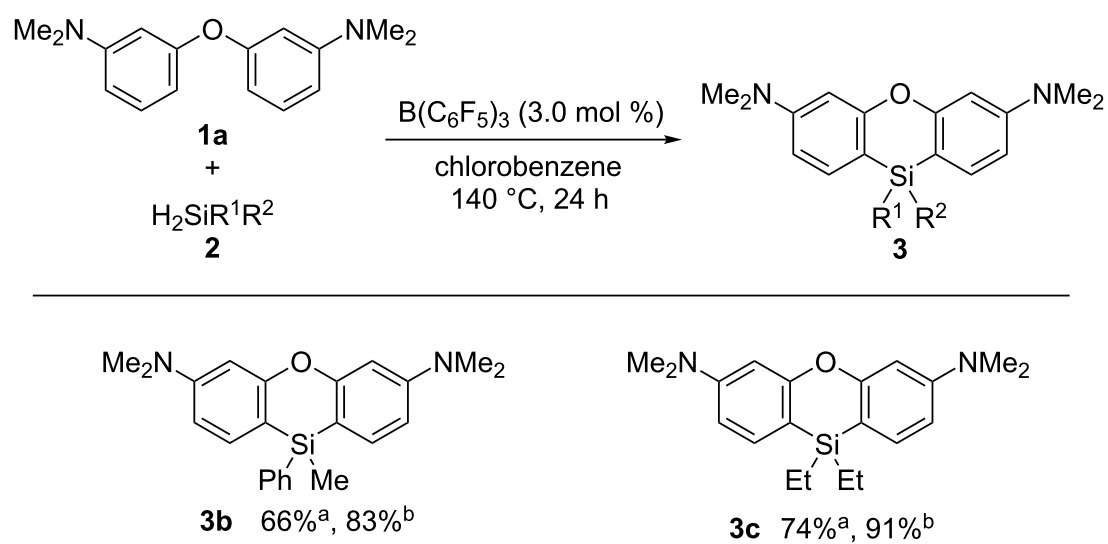

3b $66 \%^{a}, 83 \%$ b

3c $74 \%^{a}, 91 \%$ b<smiles>[3H][Si]1([AlH])c2ccc(N(C)C)cc2Oc2cc(N(C)C)ccc21</smiles>

$\mathrm{Ph}$ ' $\mathrm{H}$

3d $59 \%$ a, $63 \%$ b

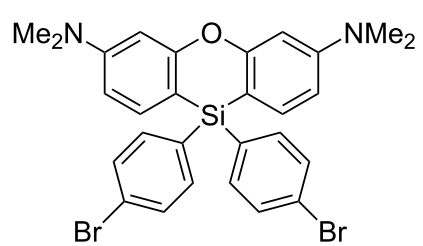

3 e $83 \%^{a}$

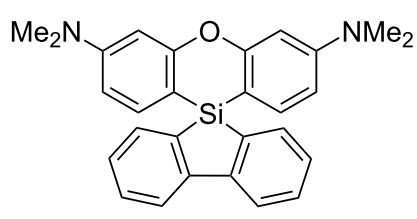

3f $96 \%$ a

Scheme 2: Scope of dihydrosilanes. Conditions: a: conditions B (Table 1, entry 5); b: conditions A (Table 1, entry 3). 

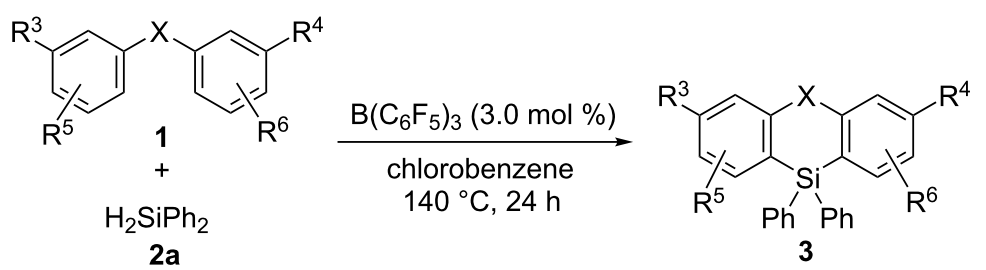

3<smiles>c1ccc(-c2ccc3cc2Oc2cc(N4CCCC4)ccc2[Si]3(c2ccccc2)c2ccc(N3CCCC3)cc2)cc1</smiles><smiles>CN(C)c1ccc2c(c1)Oc1cc(N(C)C)c(Cl)cc1[Si]2(c1ccccc1)c1ccccc1</smiles>

3 g $80 \%$ a

3h $94 \%^{a}$<smiles>Cc1cc2c(cc1N(C)C)[Si](c1ccccc1)(c1ccccc1)c1ccc(N(C)C)cc1O2</smiles><smiles>Cc1cc(N(C)C)cc2c1[Si](c1ccccc1)(c1ccccc1)c1ccc(N(C)C)cc1O2</smiles>

3i $99 \%^{a}$<smiles>CN(C)c1ccc2c(c1)Oc1cc(C(C)(C)C)ccc1[Si]2(c1ccccc1)c1ccccc1</smiles>

3k $68 \%$ b,c 3j $74 \%^{\mathrm{a}}, 81 \%^{\mathrm{b}}$<smiles>c1ccc(-c2ccc3cc2Sc2cc(N4CCCC4)ccc2[Si]3(c2ccccc2)c2ccc(N3CCCC3)cc2)cc1</smiles>

3) $93 \%^{a}$<smiles>CN(Cc1ccccc1)c1ccc2c(c1)Sc1cc(N(C)Cc3ccccc3)ccc1[Si]2(c1ccccc1)c1ccccc1</smiles>

Scheme 3: Scope of diaryl ether and diaryl thioether derivatives. Conditions: a: conditions B (Table 1, entry 5); b: conditions A (Table 1, entry 3). C: temperature $180^{\circ} \mathrm{C}$.
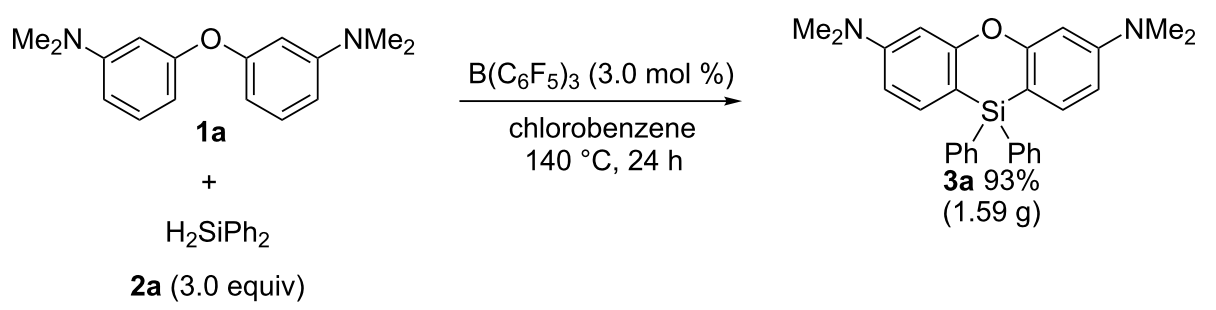

Scheme 4: Gram-scale Synthesis of 3a.

diaryl ether 1a (1.00 g) with dihydrodiphenylsilane (2a, $2.16 \mathrm{~g})$ in the presence of a catalytic amount of $\mathrm{B}\left(\mathrm{C}_{6} \mathrm{~F}_{5}\right)_{3}$ afforded phenoxasilin 3a in 93\% yield (1.59 g).

Finally, the transformation of the amino groups in phenoxasilin 3a into phenyl groups was carried out (Scheme 5). First, the ammonium salt $\mathbf{4}$ was prepared by treating $\mathbf{3 a}$ with MeOTf fol- lowed by a palladium-catalyzed cross-coupling reaction with the Grignard reagent $(\mathrm{PhMgBr})$ that afforded the desired diphenylated phenoxasilin 5 in $87 \%$ yield [43].

\section{Conclusion}

In summary, we have developed a new catalytic synthetic method to prepare six-membered silacyclic compounds, such as 
<smiles>CN(C)c1ccc2c(c1)Oc1cc(N(C)C)ccc1[Si]2(c1ccccc1)c1ccccc1</smiles>

3a $\frac{\text { MeOTf (2.2 equiv) }}{\mathrm{CH}_{2} \mathrm{Cl}_{2}, 25^{\circ} \mathrm{C}, 2 \mathrm{~h}}$

(1)

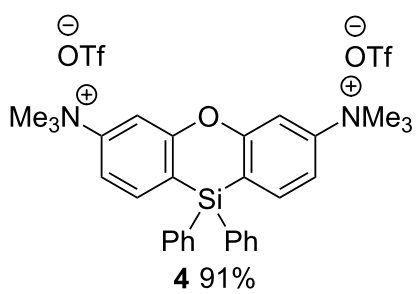

$491 \%$

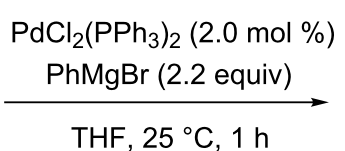

THF, $25^{\circ} \mathrm{C}, 1 \mathrm{~h}$<smiles>[Pb]P([PbH2])[Si]1(c2ccccc2)c2ccc(-c3ccccc3)cc2Oc2cc(-c3ccccc3)ccc21</smiles>

Scheme 5: Transformation of the amino groups in $\mathbf{3 a}$.

phenoxasilin and phenothiasilin derivatives, using a double silaFriedel-Crafts reaction. The reaction system is applicable to diaryl ethers with halogen substituents or sterical hindrance. A gram-scale synthesis of phenoxasilins and transformation of the amino groups in the phenoxasilin product were also achieved. We hope that the developed protocol will prove to be a useful and efficient method to synthesize six-membered silacyclic compounds.

\section{Supporting Information}

\section{Supporting Information File 1}

Experimental procedures, compounds characterization data, and copies of ${ }^{1} \mathrm{H}$ and ${ }^{13} \mathrm{C}$ NMR spectra.

[https://www.beilstein-journals.org/bjoc/content/ supplementary/1860-5397-16-39-S1.pdf]

\section{Supporting Information File 2}

CIF file for $3 \mathbf{a}$.

[https://www.beilstein-journals.org/bjoc/content/ supplementary/1860-5397-16-39-S2.cif]

\section{Funding}

This work was supported in part by JSPS KAKENHI Grant Numbers JP 17H03016 and 18H04656, The Sumitomo Foundation, and A-STEP (VP30218088652) from JST. Y.D. is grateful to the CSC (China Scholarship Council) for the PhD fellowship.

\section{ORCID ${ }^{\circledR}$ iDs}

Kohei Sekine - https://orcid.org/0000-0001-7588-3176 Yoichiro Kuninobu - https://orcid.org/0000-0002-8679-9487

\section{References}

1. Li, J.; Ding, D.; Wei, Y.; Zhang, J.; Xu, H. Adv. Opt. Mater. 2016, 4, 522-528. doi:10.1002/adom.201500673

2. Hayashi, H.; Nakao, H.; Miyabayashi, T.; Murase, M. Jpn. J. Appl. Phys. 2013, 52, 05DA13. doi:10.7567/jjap.52.05da13

3. Sun, J. W.; Baek, J. Y.; Kim, K.-H.; Moon, C.-K.; Lee, J.-H.; Kwon, S.-K.; Kim, Y.-H.; Kim, J.-J. Chem. Mater. 2015, 27, 6675-6681. doi:10.1021/acs.chemmater.5b02515

4. Matsuo, K.; Yasuda, T. Chem. Sci. 2019, 10, 10687-10697. doi:10.1039/c9sc04492b

5. Kranenburg, M.; van der Burgt, Y. E. M.; Kamer, P. C. J.; van Leeuwen, P. W. N. M.; Goubitz, K.; Fraanje, J. Organometallics 1995, 14, 3081-3089. doi:10.1021/om00006a057

6. Kranenburg, M.; Kamer, P. C. J.; van Leeuwen, P. W. N. M. Eur. J. Inorg. Chem. 1998, 25-27. doi:10.1002/(sici)1099-0682(199801)1998:1<25::aid-ejic25>3.0.co;2-k

7. van der Veen, L. A.; Keeven, P. H.; Schoemaker, G. C.; Reek, J. N. H.; Kamer, P. C. J.; van Leeuwen, P. W. N. M.; Lutz, M.; Spek, A. L. Organometallics 2000, 19, 872-883. doi:10.1021/om990734o

8. Bronger, R. P. J.; Kamer, P. C. J.; van Leeuwen, P. W. N. M. Organometallics 2003, 22, 5358-5369. doi:10.1021/om034012f

9. Clayden, J.; Fletcher, S. P.; Senior, J.; Worrall, C. P. Tetrahedron: Asymmetry 2010, 21, 1355-1360. doi:10.1016/j.tetasy.2010.06.017

10. Rajesh, K.; Dudle, B.; Blacque, O.; Berke, H. Adv. Synth. Catal. 2011, 353, 1479-1484. doi:10.1002/adsc.201000867

11. Corey, J. Y.; Corey, E. R.; Chang, V. H. T.; Hauser, M. A.; Leiber, M. A.; Reinsel, T. E.; Riva, M. E. Organometallics 1984, 3 , 1051-1060. doi:10.1021/om00085a015

12. Betson, M. S.; Clayden, J.; Worrall, C. P.; Peace, S. Angew. Chem., Int. Ed. 2006, 45, 5803-5807. doi:10.1002/anie.200601866

13. Betson, M. S.; Clayden, J. Synlett 2006, 745-746 doi:10.1055/s-2006-933111

14. Braddock-Wilking, J.; Corey, J. Y.; French, L. M.; Choi, E.; Speedie, V. J.; Rutherford, M. F.; Yao, S.; Xu, H.; Rath, N. P. Organometallics 2006, 25, 3974-3988. doi:10.1021/om060391b 15. Oita, K.; Gilman, H. J. Am. Chem. Soc. 1957, 79, 339-342. doi:10.1021/ja01559a026 
16. Hitchcock, C. H. S.; Mann, F. G.; Vanterpool, A. J. Chem. Soc. 1957, 4537-4546. doi:10.1039/jr9570004537

17. Gilman, H.; Miles, D. J. Org. Chem. 1958, 23, 1363-1365. doi:10.1021/jo01103a036

18. Gilman, H.; Trepka, W. J. J. Org. Chem. 1961, 26, 5202-5203. doi:10.1021/jo01070a512

19. Gilman, H.; Trepka, W. J. J. Org. Chem. 1962, 27, 1418-1422. doi:10.1021/jo01051a071

20. Belsky, V. K.; Saratov, I. E.; Reikhsfeld, V. O.; Simonenko, A. A. J. Organomet. Chem. 1983, 258, 283-289. doi:10.1016/s0022-328x(00)99273-8

21. Corey, J. Y.; Trankler, K. A.; Braddock-Wilking, J.; Rath, N. P. Organometallics 2010, 29, 5708-5713. doi:10.1021/om100544f

22. Wittenberg, D.; McNinch, H. A.; Gilman, H. J. Am. Chem. Soc. 1958, 80, 5418-5422. doi:10.1021/ja01553a025

23. McCarthy, W. Z.; Corey, J. Y.; Corey, E. R. Organometallics 1984, 3 , 255-263. doi:10.1021/om00080a016

24. van der Boon, L. J. P.; Hendriks, J. H.; Roolvink, D.; O'Kennedy, S. J.; Lutz, M.; Slootweg, J. C.; Ehlers, A. W.; Lammertsma, K. Eur. J. Inorg. Chem. 2019, 3318-3328. doi:10.1002/ejic.201900641

25. Onoe, M.; Morioka, T.; Tobisu, M.; Chatani, N. Chem. Lett. 2013, 42, 238-240. doi:10.1246/cl.2013.238

26. Li, H.; Wang, Y.; Yuan, K.; Tao, Y.; Chen, R.; Zheng, C.; Zhou, X.; Li, J.; Huang, W. Chem. Commun. 2014, 50, 15760-15763. doi:10.1039/c4cc06636g

27. Sato, Y.; Takagi, C.; Shintani, R.; Nozaki, K. Angew. Chem., Int. Ed. 2017, 56, 9211-9216. doi:10.1002/anie.201705500

28. Bhr, S.; Oestreich, M. Angew. Chem., Int. Ed. 2017, 56, 52-59. doi:10.1002/anie.201608470

29. Richter, S. C.; Oestreich, M. Trends Chem. 2020, 2, 13-27. doi:10.1016/j.trechm.2019.07.003

30. Furukawa, S.; Kobayashi, J.; Kawashima, T. J. Am. Chem. Soc. 2009, 131, 14192-14193. doi:10.1021/ja906566r

31. Furukawa, S.; Kobayashi, J.; Kawashima, T. Dalton Trans. 2010, 39, 9329-9336. doi:10.1039/c0dt00136h

32. Arii, H.; Nakabayashi, K.; Mochida, K.; Kawashima, T. Molecules 2016, 21, 999. doi:10.3390/molecules21080999

33. Curless, L. D.; Ingleson, M. J. Organometallics 2014, 33, 7241-7246. doi:10.1021/om501033p

34. Omann, L.; Oestreich, M. Angew. Chem., Int. Ed. 2015, 54, 10276-10279. doi:10.1002/anie.201504066

35. Chen, Q.-A.; Klare, H. F. T.; Oestreich, M. J. Am. Chem. Soc. 2016, 138, 7868-7871. doi:10.1021/jacs.6b04878

36. Yin, Q.; Klare, H. F. T.; Oestreich, M. Angew. Chem., Int. Ed. 2016, 55, 3204-3207. doi:10.1002/anie.201510469

37. Ma, Y.; Wang, B.; Zhang, L.; Hou, Z. J. Am. Chem. Soc. 2016, 138, 3663-3666. doi:10.1021/jacs.6b01349

38. Han, Y.; Zhang, S.; He, J.; Zhang, Y. J. Am. Chem. Soc. 2017, 139, 7399-7407. doi:10.1021/jacs.7b03534

39. Omann, L.; Oestreich, M. Organometallics 2017, 36, 767-776. doi:10.1021/acs.organomet.6b00801

40. Dong, Y.; Takata, Y.; Yoshigoe, Y.; Sekine, K.; Kuninobu, Y. Chem. Commun. 2019, 55, 13303-13306. doi:10.1039/c9cc07692a

41. Ureshino, T.; Yoshida, T.; Kuninobu, Y.; Takai, K. J. Am. Chem. Soc. 2010, 132, 14324-14326. doi:10.1021/ja107698p See for Rhodium-catalyzed intramolecular $\mathrm{C}-\mathrm{H}$ silylation for the synthesis of silafluorenes.
42. CCDC 1979913 (3a) contains the supplementary crystallographic data for this paper. The data can be obtained free of charge from The Cambridge Crystallographic Data Centre via https://www.ccdc.cam.ac.uk/structures/.

43. Reeves, J. T.; Fandrick, D. R.; Tan, Z.; Song, J. J.; Lee, H.; Yee, N. K.; Senanayake, C. H. Org. Lett. 2010, 12, 4388-4391. doi:10.1021/ol1018739

\section{License and Terms}

This is an Open Access article under the terms of the Creative Commons Attribution License

(http://creativecommons.org/licenses/by/4.0). Please note that the reuse, redistribution and reproduction in particular requires that the authors and source are credited.

The license is subject to the Beilstein Journal of Organic Chemistry terms and conditions:

(https://www.beilstein-journals.org/bjoc)

The definitive version of this article is the electronic one which can be found at: doi:10.3762/bjoc. 16.39 